\title{
Steps toward accurate large-area analyses of Genesis solar wind samples: evaluation of surface cleaning methods using total reflection X-ray fluorescence spectrometry
}

\author{
Martina Schmeling, ${ }^{1, a)}$ Donald S. Burnett, ${ }^{2}$ Amy J. G. Jurewicz, ${ }^{3}$ and Igor V. Veryovkin ${ }^{4}$ \\ ${ }^{\prime}$ Loyola University Chicago, Chicago, Illinois 60660 \\ ${ }^{2}$ California Institute of Technology, Pasadena, California 91125 \\ ${ }^{3}$ Arizona State University, Tempe, Arizona 85287 \\ ${ }^{4}$ Argonne National Laboratory, Argonne, Illinois 60439
}

(Received 1 March 2012; accepted 10 March 2012)

\begin{abstract}
Total reflection X-ray fluorescence spectrometry (TXRF) was used to analyze residual surface contamination on Genesis solar wind samples and to evaluate different cleaning methods. To gauge the suitability of a cleaning method, two samples were analyzed following cleaning by lab-based TXRF. The analysis comprised an overview and a crude manual mapping of the samples by orienting them with respect to the incident X-ray beam in such a way that different regions were covered. The results show that cleaning with concentrated hydrochloric acid and a combination of hydrochloric acid and hydrofluoric acid decreased persistent inorganic contaminants substantially on one sample. The application of $\mathrm{CO}_{2}$ snow for surface cleaning tested on the other sample appears to be effective in removing one persistent Genesis contaminant, namely germanium. Unfortunately, the TXRF analysis results of the second sample were impacted by relatively high background contamination. This was mostly due to the relatively small sample size and that the solar wind collector was already mounted with silver glue for resonance ion mass spectrometry (RIMS) on an aluminium stub. Further studies are planned to eliminate this problem. In an effort to identify the location of very persistent contaminants, selected samples were also subjected to environmental scanning electron microscopy. The results showed excellent agreement with TXRF analysis. (c) 2012 International Centre for Diffraction Data. [doi:10.1017/S0885715612000346]
\end{abstract}

Key words: total reflection X-ray fluorescence spectrometry, genesis solar samples

\section{INTRODUCTION}

The NASA Genesis mission is the first mission returning solar material to Earth for laboratory analysis after the Apollo program (Burnett et al., 2003). Solar wind (SW) was collected by passively exposing ultrapure materials such as silicon and sapphire $\left(\mathrm{Al}_{2} \mathrm{O}_{3}\right)$, mounted on a small spacecraft, to the charged particles (Jurewicz et al., 2003). The collection took place at Lagrange 1 (L1) point, where gravities of Sun and Earth are equal, for a duration of 854 days (Reisenberg et al., 2005). The space craft returned to Earth on September 8, 2004 with an unexpected crash landing in the Utah desert. The impact not only fractured the collectors into small irregular pieces but also broke the retum capsule open exposing the collectors to the desert environment. As a result samples were contaminated and have to be cleaned individually before any analyses of SW material can be carried out. The ubiquitous contaminants are separated from the atoms of SW by only $5-15 \mathrm{~nm}$, presenting significant challenges for SW analyses as well as the development of cleaning techniques. The contamination varies from sample to sample, but consists primarily of two types: an organic silicone-like film acquired in flight and particulates from the hard landing. Different surface cleaning procedures for removal of both types of contaminations were and are still being developed to enable analysis of minor SW elements prominent also in the contamination (Huang et al., 2006, 2008; Sestak et al., 2006;

\footnotetext{
a) Author to whom correspondence should be addressed. Electronic mail: mschmel@luc.edu
}

Allton et al., 2007; Calaway et al., 2007, 2009; Schmeling et al., 2011).

Each sample has to be checked after cleaning to decide whether removal of contaminants was successful and to guide what, if any additional cleaning steps are required. Analysis methods employed for post-cleaning control have to be surface sensitive and non-destructive to avoid additional contamination. They also have to be fast and multi-element capable to accommodate the large number of samples. Bench-top total reflection X-ray fluorescence spectrometry (TXRF) offers all these features as it is a non-destructive, surface sensitive analysis method with detection limits in the lower $10^{11}$ to $10^{9}$ atoms $\mathrm{cm}^{-2}$ range (Klockenkämper, 1997; Wobrauschek, 1998, 2007; Streli et al., 1999; Shaffner, 2000; Pahlke et al., 2001; Hellin et al., 2006; Schmeling, 2005; Sekowski et al., 2008; West et al., 2010; Schmeling et al., 2011).

To date a total of 18 different Genesis samples consisting of silicon, silicon on sapphire and sapphire were analyzed using bench top TXRF after applying different methods of surface cleaning. Two samples treated by very different surface cleaning methods were selected for this study to demonstrate the capability of bench-top TXRF and also to highlight the challenges faced with this type of sample. The results indicate that each material is unique and requires a specific cleaning approach, which often has to be adapted for Genesis samples.

\section{INSTRUMENTATION AND METHODS}

Most sample analysis was carried out with a PicoTax ${ }^{\circledast}$ TXRF spectrometer utilizing a fine focus X-ray tube with 
Mo target ( $40 \mathrm{kV}$ and $1000 \mu \mathrm{A}$ operating conditions). Some of the samples were analyzed with the newly acquired S2 Pico Fox TXRF spectrometer equipped with a micro focus $\mathrm{X}$-ray tube with Mo target $(40 \mathrm{kV}, 600 \mu \mathrm{A})$ and a curved multilayer, focusing the X-ray beam on the sample. Both instruments are equipped with a silicon drift detector and were manufactured by Bruker AXS, Berlin, Germany. The sample spot size for the Pico Tax ${ }^{\circledast}$ instrument is about $2 \mathrm{~mm}$ (width) $\times$ $5 \mathrm{~mm}$ (length) and for the S2 PicoFox instrument $0.1 \mathrm{~mm}$ (width) $\times 5 \mathrm{~mm}$ (length).

Since both instruments use vertical loading of the sample, they were tilted $90^{\circ}$ and supported in a frame structure to allow for horizontal loading of the Genesis samples. Special polycarbonate templates were made having an area large enough for the Genesis sample to be placed into a pocket of appropriate depth milled out of the material to make a flush surface of sample and carrier. Figure 1 shows a template together with a sample. The templates were cleaned by ultrasonication in soapy water, then rinsed with $18-\mathrm{MOhm}$ water and checked for contamination before each analysis. The Genesis sample was then placed carefully into the cleaned template using polytetrafluoroethylene (PTFE) tweezers in a class 100 clean bench and transferred to the TXRF instrument in a closed container to avoid contamination during transport. TXRF analysis of the samples was carried out with counting times of $7200 \mathrm{~s}$ for PicoTax ${ }^{\otimes}$ and 2000 s for S2 PicoFox instrument, respectively. Higher sensitivity permitted for shorter measurement

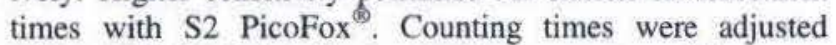
when needed to determine contaminations present. The detection limits (in atoms $\mathrm{cm}^{-2}$ ) for a counting time of $7200 \mathrm{~s}$ for both instruments are shown in Table I.

All samples were analyzed by TXRF after being cleaned with ultrapure water (UPW) and some samples were cleaned with UV Ozone at Johnson Space Center, which removes many of the larger particulates and organic materials, respectively (Allton et al., 2007; Calaway et al., 2007, 2009). Two approaches for cleaning were then investigated: (1) Acid cleaning for sample sapphire $\left(\mathrm{Al}_{2} \mathrm{O}_{3}\right) 50719$ and (2) $\mathrm{CO}_{2}$

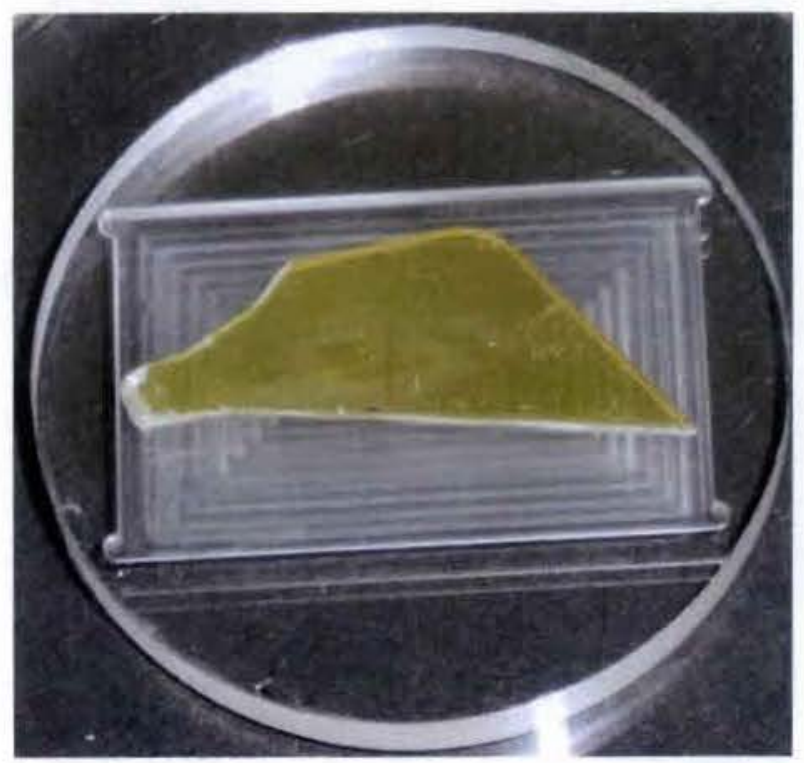

Figure 1. (Color online) A NASA Genesis SW sample (silicon on sapphire) as placed in a polycarbonate analysis template, specifically made for this purpose.
TABLE I. Detection limits for selected elements measured with PicoTax and PicoTax. Counting time $7200 \mathrm{~s}$.

\begin{tabular}{|c|c|c|}
\hline Element & PicoTax (atoms $\mathrm{cm}^{-2}$ ) & PicoFox (atoms $\mathrm{cm}^{-2}$ ) \\
\hline $\mathrm{K}$ & $9 \times 10^{11}$ & $2 \times 10^{11}$ \\
\hline $\mathrm{Ca}$ & $6 \times 10^{11}$ & $1 \times 10^{11}$ \\
\hline $\mathrm{Cr}$ & $2 \times 10^{11}$ & $3 \times 10^{10}$ \\
\hline Mn & $2 \times 10^{11}$ & $4 \times 10^{10}$ \\
\hline $\mathrm{Fe}$ & $1 \times 10^{11}$ & $2 \times 10^{10}$ \\
\hline $\mathrm{Ni}$ & $8 \times 10^{10}$ & $1 \times 10^{10}$ \\
\hline $\mathrm{Zn}$ & $5 \times 10^{10}$ & $9 \times 10^{9}$ \\
\hline $\mathrm{Ga}$ & $7 \times 10^{10}$ & $1 \times 10^{10}$ \\
\hline $\mathrm{Ge}$ & $4 \times 10^{10}$ & $6 \times 10^{9}$ \\
\hline $\mathrm{Rb}$ & $4 \times 10^{10}$ & $8 \times 10^{9}$ \\
\hline $\mathrm{Sr}$ & $4 \times 10^{10}$ & $6 \times 10^{9}$ \\
\hline $\mathrm{Pb}$ & $1 \times 10^{10}$ & $4 \times 10^{9}$ \\
\hline
\end{tabular}

snow cleaning for sample silicon 60758. For (1) Sample 50719 was subjected to a $6 \mathrm{M}$ hydrochloric acid cleaning cycle analyzed by TXRF and then underwent a second more rigorous cleaning step involving hydrofluoric (1:5) and hydrochloric acid $(6 \mathrm{M})$. In case (2) sample 60578 was placed in a $\mathrm{CO}_{2}$ snow cleaning apparatus based on the system manufactured by Applied Surface Technologies (New Providence, $\mathrm{NJ}$; high purity unit K4-10, http://www.co2clean.com). This sample was placed in a sealed chamber, which was purged with dry nitrogen for $2 \mathrm{~h}$ prior to raster scanning the surface of the sample with a $\mathrm{CO}_{2}$ snow jet for about $30 \mathrm{~min}$. TXRF analysis was carried out before and after $\mathrm{CO}_{2}$ cleaning.

The acid-treated sample was also investigated by scanning electron microscopy (FEI XL 30) to locate and identify remnant particulate contamination.

\section{RESULTS}

\section{A. Acid cleaning - NASA Genesis SW sample sapphire 50719}

NASA Genesis sample sapphire $\left(\mathrm{Al}_{2} \mathrm{O}_{3}\right) 50719$ underwent three cleaning steps as described under (1) in the experimental section with subsequent analysis by TXRF. Figure 2 shows TXRF analysis results using the PicoTax ${ }^{\circledast}$ instrument following each cleaning step. The green spectrum shows the results obtained after UPW and $\mathrm{UV} / \mathrm{O}_{3}$ treatment, the blue spectrum was recorded after $6 \mathrm{M} \mathrm{HCl}$ cleaning and the red spectrum shows the results after additional cleaning with 1:5 $\mathrm{HF}: \mathrm{H}_{2} \mathrm{O}$ and $6 \mathrm{M} \mathrm{HCl}$. Clearly noticeable is the difference in background scattering for the spectra before and after the first acid cleaning, especially pronounced in the lower energy range. The elevated background for the green spectrum (before acid cleaning) most likely indicates the presence of the film-like organic surface contamination acquired in flight, which appears to be removed by $6 \mathrm{M}$ hydrochloric acid treatment. The large peak remaining after $6 \mathrm{M} \mathrm{HCl}$ and somewhat reduced after second acid cleaning with $\mathrm{HF}$ and $\mathrm{HCl}$ corresponds to germanium. Some of the collectors were made of high purity germanium and were pulverized during the crash. As a result most collector fragments show germanium contamination to a certain degree. Inspection using scanning electron microscopy of the same area analyzed by TXRF yields also germanium as contaminant. An estimation of contamination remaining after each analysis step was attempted. For this, the count rate of the element(s) measured on the 


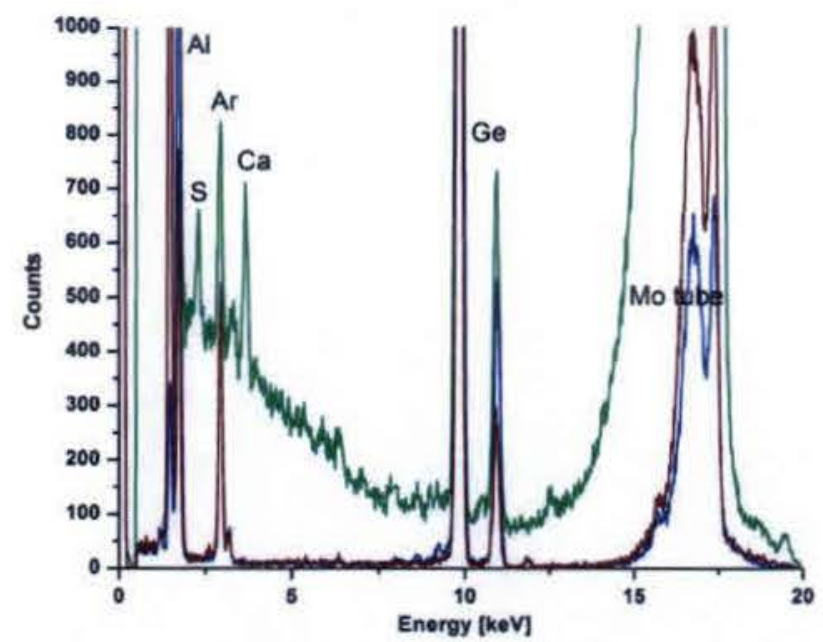

Figure 2. (Color online) Spectra obtained after different cleaning steps for sample $\mathrm{Al}_{2} \mathrm{O}_{3}$ 50719. The green (light gray) spectrum was acquired after routine cleaning with UPW and $\mathrm{UV} / \mathrm{O}_{3}$ (Allton et al., 2007), the blue (dark gray) spectrum was measured after cleaning the sample with $6 \mathrm{M} \mathrm{HCl}$ and the red (black) spectrum corresponds to the sample after an additional cleaning step with $1: 5 \mathrm{HF}: \mathrm{H}_{2} \mathrm{O}$ and $6 \mathrm{M} \mathrm{HCl}$.

sample surface was compared to the count rate of a standard containing known concentrations of the element in the same order of magnitude than the sample. The counting time was the same as the sample. Table II shows the rough estimates. It is important to keep in mind that these rough estimates are indicating only the order of magnitude of contamination and not the exact amount.

\section{B. $\mathrm{CO}_{2}$ snow cleaning - NASA Genesis SW sample silicon 60758}

Another Genesis sample, 60758, made of silicon, was subjected to a different cleaning approach using $\mathrm{CO}_{2}$ snow as described in the experimental section. $\mathrm{CO}_{2}$ snow is widely used as a cleaning step in the semiconductor industry. $\mathrm{CO}_{2}$ cleaning is gentle and fast and does not attack the material itself, but only removes particles located at the surface of the substrate. The sample was already mounted on a stub for resonance ion mass spectrometry (RIMS) analysis and special polycarbonate templates were made accountable. The templates had markers to ensure that the sample was loaded in the same position into the TXRF spectrometer each time, before and after cleaning. The sample was analyzed with both the PicoTax ${ }^{\infty}$ and the S2PicoFox ${ }^{\infty}$ instruments before and after cleaning with $\mathrm{CO}_{2}$ snow. The older PicoTax ${ }^{\circledR}$ instrument has a larger analysis spot with $5 \mathrm{~mm}$ in length and $2 \mathrm{~mm}$ in width and thus provides a good overview measurement of the sample. The newer S2 PicoFox instrument has an

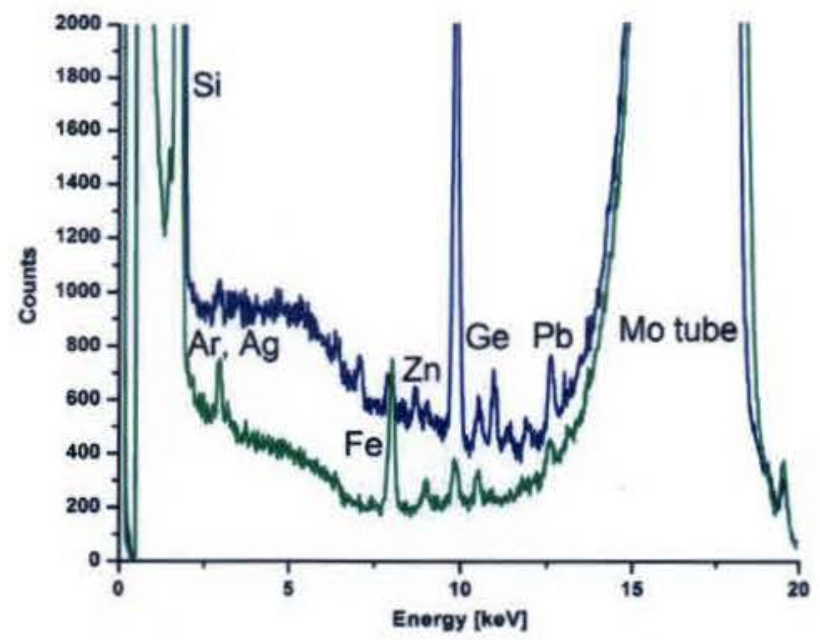

Figure 3. (Color online) Analysis of sample Si 60758 by PicoTax TXRF spectrometer with spot size $5 \mathrm{~mm}$ length and $2 \mathrm{~mm}$ width. The blue (dark gray) spectrum shows the sample before $\mathrm{CO}_{2}$ cleaning, whereas the green (light gray) spectrum shows the sample after $\mathrm{CO}_{2}$ cleaning.

analysis spot size of $5 \mathrm{~mm}$ in length and $0.1 \mathrm{~mm}$ in width, thus making it possible to obtain some crude surface mapping when the sample is moved systematically with respect to the beam. This was achieved by using different templates, which held the sample in different off-set positions from the center of the beam spot. The sample itself was about $5 \mathrm{~mm}$ in one direction and about $4 \mathrm{~mm}$ in the other direction. As the sample was already fixed on a stub, sometimes several spectra were necessary to ensure that proper total reflection of the X-ray beam on the sample surface was achieved. Figures 3 and 4 show the results obtained with PicoTax (Figure 3 ) and S2 PicoFox ${ }^{\circledR}$ (Figure 4) before and after the $\mathrm{CO}_{2}$ cleaning step. The initial contamination of the sample is shown as the blue spectrum in Figures 3 and 4 . The green spectra in Figures 3 and 4 show the results after $\mathrm{CO}_{2}$ cleaning of the sample. It is important to note that the sample was mounted with glue containing mostly silver but also other elements. Possibly the peaks of $\mathrm{Fe}, \mathrm{Cu}, \mathrm{Zn}, \mathrm{Pb}$ and $\mathrm{Bi}$ originate besides the $\mathrm{Ag}$ from the glue as the $\mathrm{X}$-ray beam striking the sample is larger in one direction than the sample itself and might also irradiate the glue and aluminium mount surrounding the sample on all sides. Moreover as the sample is progressively moved away from the center of the irradiated area, more and more of the mount together with the glue and less sample is being exposed to the beam accounting for additional peaks. To clarify the source of some of the elements detected, we are in the process of measuring the glue itself and compare it with the spectra obtained for sample 60758 . The germanium peak (at $\sim 9.8 \mathrm{keV}$ ) very likely originates from the sample and was noticeably reduced after $\mathrm{CO}_{2}$ cleaning

TABLE II. Estimated concentrations of remaining surface contaminants after each cleaning step.

\begin{tabular}{|c|c|c|c|}
\hline Element & 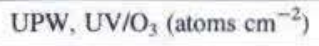 & $6 \mathrm{M} \mathrm{HCl}$ (atoms $\mathrm{cm}^{-2}$ ) & $1: 5 \mathrm{HF} ; 6 \mathrm{M} \mathrm{HCl}$ (atoms $\mathrm{cm}^{-2}$ ) \\
\hline $\mathrm{Ca}$ & $2 \times 10^{13}$ & & \\
\hline $\mathrm{Fe}$ & $1 \times 10^{12}$ & $4 \times 10^{11}$ & \\
\hline $\mathrm{Zn}$ & $6 \times 10^{11}$ & $1 \times 10^{11}$ & \\
\hline $\mathrm{Ga}$ & & $6 \times 10^{10}$ & $9 \times 10^{10}$ \\
\hline $\mathrm{Ge}$ & $2 \times 10^{13}$ & $1 \times 10^{13}$ & $2 \times 10^{12}$ \\
\hline $\mathrm{Pb}$ & $3 \times 10^{12}$ & $4 \times 10^{11}$ & \\
\hline
\end{tabular}




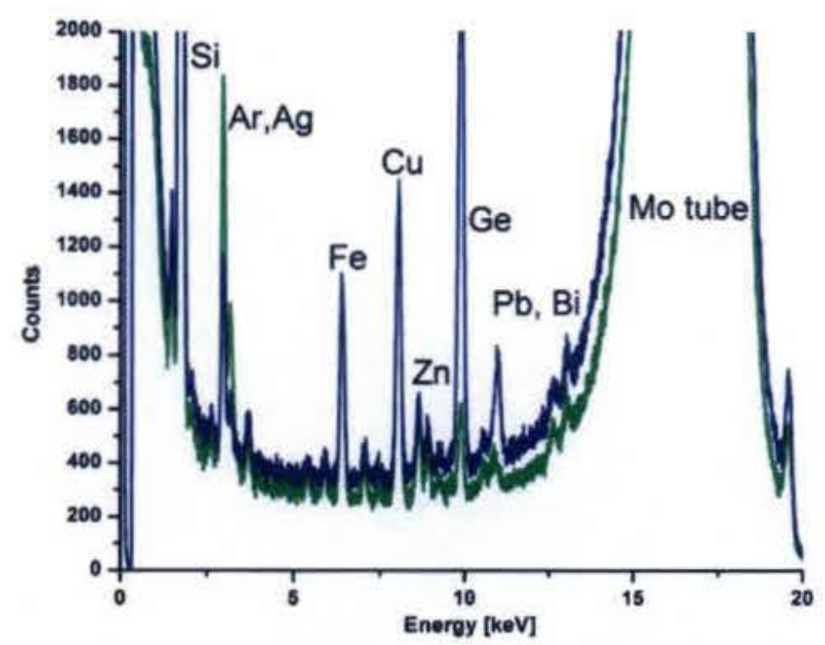

Figure 4. (Color online) Analysis of sample Si 60758 by S2 PicoFox TXRF spectrometer having a spot size of $5 \mathrm{~mm}$ in length and $0.1 \mathrm{~mm}$ in width. The blue (dark gray) spectrum shows the sample before $\mathrm{CO}_{2}$ cleaning and the green (light gray) one after $\mathrm{CO}_{2}$ cleaning.

as seen in both sets of measurements. So far these results seem to indicate that $\mathrm{CO}_{2}$ snow cleaning might be a good and gentle alternative to acid cleaning when the contaminants, like in this case $\mathrm{Ge}$, are loosely held at the surface.

\section{CONCLUSION}

Bench top TXRF spectrometry was used successfully to analyze surface contaminations on NASA Genesis SW samples before and after cleaning procedures. Two different cleaning approaches were explored and both appear to be promising. In some cases, additional measurements identifying contamination originating from sample treatment (i.e., sample glue for mounting prior to RIMS analysis) have to be carried out to identify the actual remnant Genesis contaminations.

\section{ACKNOWLEDGEMENTS}

This work was supported by NASA/JPL grant 1369203 and NASA grant NNX10AH05G. The work of I.V.V was supported by NASA through grant NNH09AM48I, and by UChicago Argonne, LLC, under contract No. DE-AC02-06CH11357. We thank C. E. Tripa for his help in preparing the $\mathrm{CO}_{2}$ snow cleaned samples,

Allton, J. H., Wentworth, S. J., Rodriguez, M. C., and Calaway, M. J. (2007). "Cleaning Genesis solar wind collectors with ultrapure water residual analysis," Lunar and Planetary Science XXXVII, Paper 2138.
Burnett, D. S., Barraclough, B. L., Bennett, R., Neugebauer, M., Oldham, L. P., Sasaki, C. N., Sevilla, S., Smith, N., Stansberry, E., Sweetnam, D., and Wiens, R. C. (2003). "The Genesis discovery mission: return of solar matter to Earth," Space Sci. Rev. 105, 509-534.

Calaway, M. J., Burnett, D. S., Rodriguez, M. C., Sestak, S., Allton, J. H., and Stansberry, E. K. (2007). "Decontamination of Genesis array materials by UV-Ozone cleaning," Lunar Planet. Sci. XXXVII, Paper 162.

Calaway, M. J., Rodriguez, M. C., Allton, J. H., and Stansberry, E. K. (2009). "Decontaminating solar wind samples with the Genesis ultrapure water megasonic spin cleaner," Lunar Planet. Sci. XXXX, Paper 1183.

Hellin, D., de Gendt, S., Valckx, N., Mertens, P. W., and Vinckier, C. (2006). "Trends in total reflection X-ray fluorescence spectrometry for metallic contamination control in semiconductor nanotechnology," Spectrochim. Acta B 61, 496-514.

Huang, S., Humayun, M., and Burnett, D. (2008). "Surficial contamination on Genesis flight silicon on sapphire (SoS) wafer fragments and its implication to the determination of solar wind tracers," Lunar Planet. Sci. XXXIX, Paper 1976

Huang, S., Humayun, M., King, S., Goddard, B., and Burnett, D. (2006). "Step cleaning experiment on the Genesis wafers," Lunar Planet. Sci XXXVII, Paper 2440.

Jurewicz, A. J. G. et al. (2003). "The Genesis solar-wind collector materials," Space Sci. Rev, 105, 535-560.

Klockenkämper, R. (1997). Total Reflection X-ray Fluorescence Analysis (Wiley and Sons, New York, NY).

Pahlke, S., Fabry, L., Kotz, L., Mantler, C., and Ehmann, T. (2001). "Determination of ultra trace contaminants on silicon wafer surfaces using TXRF "state-of-the art," Spectrochim. Acta B 56, 2261-2274.

Reisenberg, D., Wiens, R. C., Barraclough, B. L., Steinberg, J. E., DeKoning, C., Zurbuchen, T., and Burnett, D. S. (2005). "The Genesis Mission solar wind samples: collection times, estimated fluences and solar-wind conditions," Lunar Planet. Sci. XXXVI. Paper 1278.

Schmeling, M. (2005), "Total reflection X-ray fluorescence," Elsevier Encyclopedia Anal. Sci. 9, 440-448.

Schmeling, M., Burnett, D. S., and Jurewicz, A. J. G. (2011). "Surface characterization of genesis samples by total reflection X-ray fluorescence spectrometry: contaminants and roughness variations," Lunar Planet. Sci. XXXXII, Paper 2041.

Sekowski, M., Steen, C., Nutsch, A., Bimbaum, E., Burenkov, A., and Pichler, P. (2008). "Total reflection X-ray fluorescence as a sensitive analysis method for the investigation of sputtering processes," Spectrochim. Acta B 63, 1382-1386.

Sestak, S., Franchi, I. A., Verchosky, A. B., Al-Kuzee, J., Braithwaite, N St. J., and Burnett, D. S. (2006). "Application of semiconductor industry cleaning technologies for Genesis sample collectors," Lunar Planet. Sci. XXXVII, Paper \#1878.

Shaffner, T. J. (2000). "Semiconductor characterization and analytical technology", Proc, IEEE 88, 1416-1437.

Streli, C., Kregsamer, P., Wobrauschek, P., Gatterbauer, H., Görgl, R. Pianetta, P., Pahlke, S., Fabry, L., Palmetshofer, L., and Schmeling, M. (1999). "Low Z Total Reflection X-ray Fluorescence analysis-challenges and answers," Spectrochim. Acta B 54, 1433-1441.

West, M., Ellis, E. T., Potts, P. J., Streli, C., Vanhoof, C., Wegrzynek, D., and Wobrauschek, P, (2010). "Atomic spectrometry update. X-ray fluorescence spectrometry," J. Anal. At. Spectrom. 25, 1503-1545.

Wobrauschek, P. (1998). "Total reflection X-ray fluorescence spectrometric determination of trace elements in the femtogram region: a survey invited lecture," J. Anal. Atm. Spectrometry 13, 333-337.

Wobrauschek, P. (2007). "Total reflection X-ray fluorescence analysis - a review," X-ray Spectrom. 36, 289-300. 